\title{
Influence of the severity of rheumatoid arthritis on sex differences in Health Assessment Questionnaire scores
}

\author{
C M Deighton, D Surtees, D J Walker
}

\begin{abstract}
In a study of 284 consecutive patients with rheumatoid arthritis attending hospital clinics a previous observation that female patients score higher on the Stanford Health Assessment Questionnaire (HAQ) than men was confirmed. A clinical disease severity score and the spread/severity index also showed that women had more severe disease. Although scores in some categories of the HAQ were higher in women, they were not disproportionately so, providing no evidence that domestic categories of the HAQ are biased against women. A multiple regression analysis showed that the spread/severity index score was the best predictor of HAQ scores, with sex making no significant contribution. The severity of the disease adequately explained the higher HAQ scores in female patients with rheumatoid arthritis.
\end{abstract}

The Stanford Health Assessment Questionnaire (HAQ) was developed to evaluate functional ability in patients with rheumatoid arthritis, and has been adapted for use in British patients. ${ }^{2}$ It has been reported that $\mathrm{HAQ}$ scores are higher in female than in male patients with rheumatoid arthritis, ${ }^{3}$ and this could not be accounted for by clinical or laboratory measures of disease activity and severity, including Larsen's $x$ ray grading. ${ }^{4}$ If this observation is true there are several possible explanations: (a) Women have more severe and disabling disease than men, but previous studies have been on insufficient numbers. ${ }^{34}$ (b) 'Domestic functioning' questions contained in the HAQ are biased against women-for example, if a man has never opened a soap powder box he will not report difficulty in doing so. (c) Women may be less stoical than men when reporting the ease with which they do things. There is evidence to suggest that the psychological state of patients influences their HAQ score. ${ }^{5}$

We tested these possibilities further in a series of hospital patients with rheumatoid arthritis.

\section{Patients and methods}

Two hundred and eighty four consecutive patients selected only for having an available same sexed sibling with classical or definite rheumatoid arthritis according to American Rheumatism Association criteria ${ }^{6}$ attending the rheumatology outpatient clinics in Newcastle upon Tyne were asked to participate. Each patient completed an HAQ (as modified for
British patients ${ }^{2}$ ) and the following information was recorded: age; sex; disease duration; use of second line drugs; nodules; vasculitis; dry eyes; duration of morning stiffness (graded $0=$ none, $1=1-15$ minutes, $2=16-30$ minutes, $3=31-60$ minutes, $4=61-120$ minutes, $5=121-240$ minutes, $6=241-480$ minutes, $7=481$ minutes and above); Larsen's modified $x$ ray grading score $^{7}$ in 208 patients with hand radiographs taken within one year of assessment; and the distribution and severity of affected joints measured with the spread/severity index. ${ }^{8}$ This index scores each set of joints (distal interphalangeal joints, proximal interphalangeal joints, metacarpophalangeal joints, wrists, elbows, shoulders, jaw, neck, lumbar spine, hips, knees, ankles, and metatarsophalangeal joints) as $\mathbf{0}=$ normal, $1=$ tender only, $2=$ swollen only, $3=$ tender and swollen, and $4=$ deformed or operated upon. In asymmetric disease the score for the worse side was used. For sets of joints, such as the distal interphalangeal joints, the worst affected joints were the ones scored for that group. The spread/severity index score was calculated from the sum of the scores of all the sets of joints.

The results were analysed with the SPSSx and SAS programs.

\section{Results}

Of the 284 subjects studied, 227 were female and 57 male. Table 1 shows the mean HAQ and spread/severity index scores. Both scores were significantly higher in the female patients. Table 2 shows the age, disease duration, and clinical features of the disease of the two sexes. There were no significant differences in age, disease duration, or Larsen's modified $x$ ray grading score between the sexes on a MannWhitney $U$ test. Documented nodules and vasculitis were more prevalent in the men and the use of artificial tear drops and a history of second line drug use were more common in the women. These differences were not significant on a $\chi^{2}$ test.

Table 1 Mean (SD) Health Assessment Questionnaire

\begin{tabular}{llll}
\hline Sex & Number & $\begin{array}{l}\text { Mean }(S D) \\
\text { HAQ score }\end{array}$ & $\begin{array}{l}\text { Mean }(S D) \\
\text { SS index } \\
\text { score }\end{array}$ \\
\hline $\begin{array}{llll}\text { Female } & 227 & 1 \cdot 7(0 \cdot 9) & \begin{array}{l}18 \cdot 2(9 \cdot 0) \\
13 \cdot 3(6 \cdot 7)\end{array} \\
\begin{array}{l}\text { Male } \\
\text { Mann-Whitney U test }\end{array} & 57 & & \\
\quad \text { fer difference } \\
\text { z }\end{array}$ & & \\
p & & $-3 \cdot 4$ & $-4 \cdot 1$ \\
\hline
\end{tabular}

\footnotetext{
Department

Rheumatology,

Royal Victoria Infirmary,

Newcastle upon Tyne

NE1 4LP, United Kingdom.

Accepted for publication

16 July 1991

Department of
Rheumatology,
University of

Newcastle upon Tyne,

C $M$ Deighton

Department of

University of

United Kingdom
} 
The eight categories of the HAQ were analysed for differences between the sexes (Table 3). Scores in all the categories, with the exception of walking, were significantly higher in the women. We attempted to ascertain for each patient whether their score in any one category was disproportionately higher than their scores in other categories by dividing each category score by the total HAQ score, excluding the contribution made by that category. It was found that this removed the significant differences between the sexes (table 3 ).

A multiple regression analysis (excluding the $x$ ray grading, which was only available for 208 of the 284 patients) was performed to examine which variables best predict the HAQ score. Care was taken to check residuals for departures from the assumptions of a linear regression analysis. No justification was found for invalidating its use. The sample size was reduced to 267 owing to individual missing values, and one observation was deleted because it was an outlying value. Table 4 summarises the multiple regression analysis procedure. The regression equation was: HAQ score $=-0.26+0.06$ (spread/severity index score) +0.09 (duration of morning stiffness in minutes) +0.01 (age of patient in years). The spread/severity index score emerged as the best predictor of the HAQ score, accounting for $43 \%$ of the variance. Sex as a variable failed to make a significant contribution to the HAQ score. The analysis

Table 2 Demographic and clinical variables for the two sexes

\begin{tabular}{lcl}
\hline Variable & $\begin{array}{l}\text { Female } \\
(n=227)\end{array}$ & $\begin{array}{l}\text { Male } \\
(n=57)\end{array}$ \\
\hline $\begin{array}{l}\text { Mean (SD) age (years) } \\
\begin{array}{l}\text { Mean (SD) duration of } \\
\text { disease (years) }\end{array}\end{array}$ & $55 \cdot 8(12 \cdot 1)$ & $56 \cdot 8(9 \cdot 9)$ \\
$\begin{array}{l}\text { Mean (SD) modified Larsen's } \\
\text { radiographic grading }\end{array}$ & $12 \cdot 5(12 \cdot 2)$ & $11 \cdot 9(11 \cdot 1)$ \\
$\begin{array}{l}\text { No(\%) with nodules } \\
\text { No(\%) with vasculitis }\end{array}$ & $\begin{array}{l}22 \cdot 7(11 \cdot 2) \\
\text { No(\%) using artificial } \\
\text { tear drops }\end{array}$ & $\begin{array}{l}19 \cdot 8(10 \cdot 1) \\
24(42)\end{array}$ \\
$\begin{array}{l}\text { No(\%) with history of second } \\
\text { line drug use }\end{array}$ & $37(16)$ & $3(5)$ \\
\hline
\end{tabular}

was repeated for the 208 patients for whom the $x$ ray grading was available. In this model the spread/severity index score accounted for $44.8 \%$ of the variance, morning stiffness $8 \cdot 8 \%$, age $4 \cdot 8 \%$, sex $3 \cdot 5 \%$, and $x$ ray grading $3 \cdot 3 \%$.

\section{Discussion}

In agreement with a small previous study ${ }^{3}$ we have confirmed a significantly higher HAQ score in women than in men. This was found despite a lack of difference between the sexes for age, disease duration, $x$ ray grading, and extra-articular manifestations. The higher score on the clinical score of disease severity (spread/ severity index) in the female patients was highly significant, and this was not explained by age or disease duration. Several previous studies suggest more disabling disease in women, ${ }^{9-13}$ though, as in this study, a greater prevalence of nodules and vasculitis in men. ${ }^{14}$

The significant differences between the sexes in the scores on eight categories of the HAQ were removed by correcting for the total $\mathrm{HAQ}$ score, suggesting that there is no evidence that categories of the HAQ are biased against women.

The stepwise multiple regression analysis showed that by far the best predictor of HAQ score is the spread/severity index score, accounting for $43 \%$ of the variance. Interestingly, duration of morning stiffness emerged at step 2, but we found no significant difference between women and men for this variable (medians one hour and 30 minutes respectively; $p=0.36$ on a Mann-Whitney $U$ test). This suggests that the patients' perceptions of disease activity may influence their completion of the HAQ irrespective of their sex, which did not appear as a significant contributing variable in the model.

In conclusion, rheumatoid articular disease severity seems to be worse in women than in men, as measured by the spread/severity index. There is no evidence to suggest that any HAQ categories are significantly biased against women. The best predictor of HAQ score was

Table 3 Mean scores on categories of the Health Assessment Questionnaire (HAQ) for the two sexes

\begin{tabular}{|c|c|c|c|c|}
\hline \multirow[t]{2}{*}{$H A Q$ category } & \multicolumn{2}{|c|}{ Mean score } & \multirow{2}{*}{$\begin{array}{l}\text { Mann-Whitney } \\
\text { U test }{ }^{*} \\
\text { (p value })\end{array}$} & \multirow{2}{*}{$\begin{array}{l}\text { Mann-Whitney } \\
\text { U test } \\
\text { (p values) }\end{array}$} \\
\hline & Women & Men & & \\
\hline $\begin{array}{l}\text { Dressing } \\
\text { Rising } \\
\text { Eating } \\
\text { Walking } \\
\text { Hygiene } \\
\text { Reach } \\
\text { Grip } \\
\text { Activities }\end{array}$ & $\begin{array}{l}1 \cdot 7 \\
1 \cdot 4 \\
1 \cdot 7 \\
1 \cdot 4 \\
1 \cdot 8 \\
2 \cdot 0 \\
2 \cdot 0 \\
1 \cdot 9\end{array}$ & $\begin{array}{l}1 \cdot 3 \\
1 \cdot 1 \\
1 \cdot 3 \\
1 \cdot 1 \\
1 \cdot 4 \\
1 \cdot 5 \\
1 \cdot 5 \\
1 \cdot 4\end{array}$ & $\begin{array}{l}0 \cdot 004 \\
0 \cdot 04 \\
0 \cdot 02 \\
0 \cdot 14 \\
0 \cdot 008 \\
0 \cdot 0002 \\
0 \cdot 0004 \\
0 \cdot 004\end{array}$ & $\begin{array}{l}0.46 \\
0.57 \\
0.47 \\
0.60 \\
0.83 \\
0.74 \\
0.30 \\
0.71\end{array}$ \\
\hline
\end{tabular}

"This column tests for significant differences for the HAQ category scores between the two sexes.

TThis column tests for significant differences for the HAQ category score divided by the total HAQ score, excluding the contribution made by that category for each patient-for example, dressing score/(total HAQ score-dressing score).

Table 4 Summary of a stepwise multiple regression analysis to predict Health Assessment Questionnaire scores

\begin{tabular}{llllll}
\hline Step & Variable entered & Partial $R^{2}$ & Model $R^{2}$ & $F$ & $p$ Value \\
\hline 1 & $\begin{array}{l}\text { Spread/severity } \\
\text { index score } \\
\text { Duration of } \\
\text { morning stiffness } \\
\text { in minutes }\end{array}$ & 0.43 & 0.43 & 197.4 & 0.0001 \\
2 & Age in years & 0.05 & 0.48 & 25.1 & 0.0001 \\
& 0.02 & 0.50 & 11.3 & 0.0009 \\
\hline
\end{tabular}


the spread/severity index score, with sex making no significant contribution. It seems most likely that the explanation for higher HAQ scores in women is not that they perceive themselves to be more disabled than men, but that they are more disabled. This raises interesting questions on the pathogenesis of rheumatoid arthritis.

This research was supported by the Arthritis and Rheumatism Council.

1 Fries J F, Spitz P W, Young D Y. The dimensions of health outcomes: the health assessment questionnaire disability outcomes: the health assessment questionnair

2 Kirwan J R, Reeback J S. Stanford health assessment questionnaire modified to assess disability in British patients with rheumatoid arthritis. $\mathrm{Br} \mathcal{F}$ Rheumatol 1986; 25: 206-9.

3 Pegley F S, Blake D R, Thompson P W. Functional status in male and female rheumatoid outpatients. Br $\mathcal{f}$ Rheumatol 1989; 28 (suppl 2): 78

4 Thompson P W, Pegley F S, Blake D R. Greater disability in women with rheumatoid arthritis is not related to differences in joint damage between the sexes. BrF Rheumatol 1990; 29 (suppl 2): 71 .

5 Peck J R, Smith T W, Ward J R, Milano R. Disability and depression in rheumatoid arthritis. A multi-trait, mult1method investigation. Arthritis Rheum 1989; 32: 1100-6.

6 Ropes M W, Bennett G A, Cobb S, Jacox R, Jessar R A. Revision of diagnostic criteria for rheumatoid arthritis. Bull Revision of diagnostic criteric

7 Walker D J, Griffiths I D. HLA associations are with severe rheumatoid arthritis. Dis Markers 1986; 4: 121-32.

8 Walker D J, Griffiths M, Dewar P, et al. Association of MHC antigens with susceptibility to and severity of rheumatoid arthritis in multicase families. Ann Rheum Dis 1985; 44: $519-25$.

9 Sherrer Y S, Bloch D A, Mitchell D M, Roth S H, Wolfe F, Fries J F. Disability in rheumatoid arthritis: comparison of prognostic factors across three populations. If Rheumatol 1987; 14: 705-9.

10 Feigenbaum S L, Masi A T. Prognosis in rheumatoid arthritis. A longitudinal study of newly diagnosed younger arthritis. A longitudinal study of newly diag

11 Bywaters E G L, Curwen M, Dresner E, et al. Ten-year follow-up of rheumatoid arthritis. Lancet 1960 ; ii: 1381 .

12 Cats A, Hazevoet H M. Significance of positive tests for rheumatoid factor in the prognosis of rheumatoid arthritis. A follow-up study. Ann Rheum Dis 1970; 29: 254-9.

13 Masi A T, Maidonado-Cocca J A, Kaplan S B, Feigenbaum $S \mathrm{~L}$, Chandler R W. Prospective study of the early course of rheumatoid arthritis in young adults: comparison of patients with and without rheumatoid factor positivity at entry and identification of variables correlating with outcome. Semin Arthritis Rheum 1976; 5: 299-326.

14 Erhardt C C, Mumford P A, Venables P J W, Maini R N. Factors predicting a poor life prognosis in rheumatoid arthritis: an eight year prospective study. Ann Rheum Dis 1989; 48: $7-13$. 